\title{
ROLE OF ANGANWADIS IN CHILD DEVELOPMENT: SOCIAL IMPACT ASSESSMENT OFANGANWADI CENTERS OF PUNJAB
}

\author{
Rajveer Kaur \\ Department of Sociology and Social Anthropology, Punjabi University, Patiala.
}

DOI: 10.46609/IJSSER.2021.v06i07.019 URL: https://doi.org/10.46609/IJSSER.2021.v06i07.019

\begin{abstract}
Development of children is vital for the development of society. The government of India started the Integrated Child Development Scheme (ICDS) in the year 1975 with an aim to provide essential services for the holistic development and well-being of children. The ICDS program comprises of the child development services namely supplemental nutrition, preschool education, nutrition and health education, health checkup, referral services and vaccinations. These services are provided to identify beneficiaries through Anganwadi centers. The present research paper is called out from an empirical research carried out to study the impact of Anganwadi centers in the state of Punjab. The study was conducted in 24 Anganwadi centers in the state of Punjab. The broad spectrum of services provided under the ICDS program include nutrition, primary health facilities, immunization, pre-school education, referral and health awareness so as to ensure the overall well-being of target age groups of children, pregnant women and nursing mothers. The primary focus of scheme is on extending essential health and well-being services to the beneficiaries; Supplemental nutrition services impact both health and livelihoods of the family; preschool education is essential for effective socialization of the child, and referral services provide access to essential medical diagnosis and treatment. These services affect the health and well-being of the mother-child, the livelihoods of the families, besides having vital impacts on social health.
\end{abstract}

Key Words: ICDS, Social Impacts, Anganwadi Centers, Health.

\section{INTRODUCTION}

Integrated Child Development Scheme, started by Government of India on 2nd October 1975, was a fight against hunger and malnutrition. Under this scheme, 26656 Anganwadi centres are being run in 155 ICDS blocks (146 Rural and 9 Urban) of the State. Today ICDS is the largest worldwide scheme for the development of children. The key objectives of this scheme are to improve the nutritional and health status of children in the age-group 0-6 years; to lay the 


\section{International Journal of Social Science and Economic Research}

ISSN: $2455-8834$

Volume:06, Issue:07 "July 2021"

foundation for proper psychological, physical and social development of the child; to reduce the incidence of mortality, morbidity, malnutrition and school dropout; to achieve effective coordination of policy and implementation amongst the various departments to promote child development and to enhance the capability of the mother to look after the normal health and nutritional needs of the child through proper nutrition and health education. These objectives are sought to be achieved through a package of services comprising supplemental nutrition; preschool education; health check-up; nutrition and health education; vaccination and referral services. These services are provided through Anganwadi centers with the help of Anganwadi worker and Anganwadi helper who belongs to the community caters to a population of 1000 people each. For the attainment of the objectives of ICDS, the anganwadi worker at each anganwadi centers needs to be equipped with adequate infrastructure, functional equipment, tools and drugs.

\section{Review of literature}

Most of the studies so far concentrated on the way this program was affected the children attending the anganwadi centers and the problems of anganwadi workers. Singh and Rani (2015) surveyed and assessed the facilities and nutrition allocation status being provided by anganwadi centers in the rural areas of district U S Nagar of Uttarakhand. The height and weight of the children of the anganwadi center was measured to determine the nutrition allocation during the survey. During this survey, it was revealed that only 1 per cent of girls were malnourished, while no boy was in the malnutrition category. This showed that the work of the Anganwadi center is having positive impact. In addition, Anganwadi workers were interviewed to learn about other facilities provided by the Anganwadi centers.

The study in Tamil Nadu stressed that the Mid-Day Meal Scheme was eliminated the social barriers and prejudices prevalent in Indian society. Mid-day meal reduced the sense of caste among children. Students at the school sit together and eat without seeing caste and economic background. This study had shown that the Mid-Day Meal Scheme in Tamil Nadu had eliminated the sense of caste and class among school children (Dreze and Goyal, 2003).

Rajni and Anupa (2012) conducted a comparative study on the children who did not take advantage of the facilities of Anganwadi centers in which two types of children were included, first group had children who took the facilities from the Anganwadi center as a child and the other group had children who did not avail of the facilities of Anganwadi center. They found that the children studying in Anganwadi centers performed better than other children. On the basis of these studies it can be said that such studies of social impact assessment are very important in formulating social development policies. 
International Journal of Social Science and Economic Research

ISSN: 2455-8834

Volume:06, Issue:07 "July 2021"

\section{Objectives}

The objective of this study is to know the Integrated Child Development Scheme (ICDS) implemented by the Anganwadi centers of Punjab. The study also aimed to find out the Social Impact Assessment of services provided under integrated child development scheme (ICDS) at Anganwadi centers of Punjab.

\section{Material and Methods}

The study was conducted in six districts namely Amritsar, Pathankot, Ludhiana, Barnala, Jalandhar and Shaheed Bhaghat Singh Nagar of Punjab. 24 Anganwadi centers were selected from these six districts. To collect information from 300 respondents, 10 respondents, 1Anganwadi worker, 1 Anganwadi helper, 1 Administrative officer, and 12 CDPO were selected from each Anganwadi center of selected blocks through interview and observation methods. Besides this, relevant information was collected from district programme officers, district women and child development department officials.

Primary and secondary material related to research methods was collected. Secondary material was obtained from the Department of Census, Department of Social security Women and Child Development, District Programme Office, other relevant government institutions, books, preacquired searches and internet etc. Interview schedule and observation method was used to collect primary information about research.

\section{Impact of Services of Anganwadi centers}

Most of the activities under ICDS are related to health. ICDS provides food, primary health facilities, immunization, pre-school education and health awareness camps to protect physical and mental health of children, pregnant women and nursing mothers, aged 0-3 years. Health services are the primary objective in the purposes of ICDS. These services affect the health, economy, mentality, behavior, etc. of the beneficiary group. The services operated under ICDS have different impacts-

\section{Impacts on the beneficiaries of supplemental nutrition}

The food provided under supplemental nutrition is divided into 3 categories. Breakfast with milk and pudding comes under first category; the second category includes lunch with pudding and milk, porridge and food Packet in the third category which is given to the registered beneficiaries. Most of the food provided to the beneficiaries under supplemental nutrition service, according to the information collected during the study, food positively affects the health of the beneficiary group. Children who were not getting food as needed started receiving food 


\section{International Journal of Social Science and Economic Research}

ISSN: $2455-8834$

Volume:06, Issue:07 "July 2021"

under the service which is preventing the children from malnutrition. Supplemental nutrition is very important for children's physical development which increases the child's capability to fight other diseases. Food that is supplemented with nutrition contributes to the child's physical development, and also plays a positive role in the family economy. Most of the respondents benefiting from the Anganwadi center are economically weak. There were many families who worked hard and did not have the capacity to provide supplementary nutrition to the children. The food provided under this service reduces the financial burden of the family. Thus, the services of supplemental nutrition impact both health and the economy of family by reducing their economic burden.

\section{Impact of Pre-school Education}

ICDS is related to the physical and mental development of children. Both physical and mental development is necessary for the overall development of the child. While health facilities are being provided at the Anganwadi center for child physical development and pre-school education is also provided for the mental development of children. According to one respondent, "Anganwadi Kendra is a nursery where children are prepared to send to school." Some activities are conducted at the Anganwadi center to meet the objective of pre-school education. Activities to be undertaken under pre-school education are classified into 6 categories based on the information received. In pre-school education children are also taught about physical hygiene like washing teeth every day, bathing every day, washing hands before and after meals, nailing, washing hands after going to the toilet. Children are taught counting, alphabets, colors name, shapes, identification of fruits and vegetables from pictures, poems, religious prayers and national anthems under pre-school education. The name of days and months are also taught to children in the Anganwadi center. Besides these children are also trained about the name of the child, the name of the parent, the name of the village or city and the work of doctors, teachers, police, railway stations, bus stands, post office etc. which promotes mental development of children. When a person learns something new in his life, his thoughts and hobbies also change. Thus, children learn something by going to Anganwadi centers, which changes their interest areas. Thus, the activities undertaken under pre-school education lead to the development of the child's cognitive development. In the Anganwadi center, children play team-building in the group, which gives the child the quality of competition, discipline, cooperation and leadership. All this is taught by charging fees in private play-way schools. But no fee is charged from children at the Anganwadi center which helps them to reduce the economic burden. Thus preschool education is a service in which children have intellectual development and positive socialization.

Impact of Nutrition and Health Education 
International Journal of Social Science and Economic Research

ISSN: 2455-8834

Volume:06, Issue:07 "July 2021"

Anganwadi workers make women aware of nutrition and health so that women can care for themselves, children and other members of the family. Children are made aware of physical hygiene, such as taking bath every day, cleaning teeth, washing hands before eating, nailing, etc. to protect from many diseases. Children adopt all these activities in their daily lives for clean and healthy life. Women are made aware of the food and physical development of children. Periodical awareness camps are organized under ICDS to educate children, pregnant women and nursing mothers for taking care of their health. According to most beneficiaries selected during the study, seminars on awareness of supplemental nutrition and their health and physical hygiene positively impacted the health of beneficiaries.

\section{Impact of Vaccination}

Vaccinations are given to protect children between the age of 0-6 years and pregnant women. These injections are administered at the time of birth, 6th week, 10th week, 14th week, 9 months, 16-24 months, 5-6 years, 10 years and 16 years of age. The parents of children are made aware of these at the Anganwadi Centers. They are encouraged to go to primary health centers for vaccination to promote children's health. These injections are available at very high rates in private hospitals, but are provided free of cost in government health centers. Those who cannot get these injections at a private hospital by spending money can avail of this service to live healthy life without any economic burden. Based on the information received during the research, it can be said that the immunization process is playing an important role in the health of the child and the family economy.

\section{Impact of Health Check-up}

Anganwadi centers have periodic health check-up camps to check the health of children, including physical development of children like height, baby weight, etc. The weight of the child is measured by the Anganwadi worker every month and is noted in a register. Doctors from the local primary health center come to the Anganwadi center every 3 months for a children's health check-up who provide health information to Anganwadi workers and beneficiaries. Health related requirements at the Anganwadi center provide basic food, medical facilities, tablets of iron, calcium, vitamin and facilities of immunization to children suffering from malnutrition. These facilities are very important for health of child. Thus, this service is very useful for those who cannot get their children under health check-up in a private hospital every 3 months. Based on the information received, it can be said that health screening is positively affect the child's health.

\section{Impact of Referral Services}

Children are periodically checked in the Anganwadi center. During this health checkup, ifa child 


\section{International Journal of Social Science and Economic Research}

ISSN: $2455-8834$

Volume:06, Issue:07 "July 2021"

needs special medical assistance, child is referred to nearby government hospital where treatment is given as per the need. If necessary treatment is not provided in that hospital, child is referred to P.G.I. hospital where free treatment is given to child. Based on the information received, it can be said that referral services positively affect the health of the child and livelihoods of the family.

\section{Conclusion}

The study has shown that the services to be provided at the Anganwadi centers are affected the health of the beneficiary group. Under supplemental nutrition service, children are given breakfast and lunch on 300 days of the year to cater the nutritional needs of children. Pre-school education is given for the child's cognitive development in the Anganwadi centre, which contributes to the well-being of the child. The pre-school service enhanced the qualities of cooperation, tolerance, respect, leadership qualities etc. Vaccinations are administered to prevent the diseases of children. The beneficiary group is made aware of health and physical hygiene under nutrition and health education. Children's physical development is examined at primary health care centers under ICDS. Services like health check, balanced food, pre-school education and immunization are provided for free at the Anganwadi centers, which reduces the family economic burden of the beneficiary group. These services affect the health and well-being of the mother-child, the livelihoods of the families, besides having vital impacts on social health.

\section{References}

1. Council for Social Development. 2010. Social Impact Assessment; Report of a Research Project on Social Impact Assessment of $R \& R$ Policies and Packages inIndia. New Delhi: Council for Social Development. (Internet) (Available at dolr.nic.in/Social_Impact_Assessment\%20hmm-2011.doc) (Retrieved on Oct.29,2016).

2. Dhingra Rajni, Sharma Anupa. Assessment of Anganwadi and Home Based Children on Cognitive Skills. International Review of Social Sciences and Humanities.Vol. 3, No. 2 (2012), pp. 96-108 (Internet) (Available at www.irssh.com. ISSN 2248-9010 (Online), ISSN 2250-0715) (Retrived on Jan.5, 2018).

3. Director Cencus Operation. Punajb (2011) (Internet) (Available at: https://censusindia.gov.in) (Retrieved on July.27, 2020).

4. Dreze and Goyal. 2003. Implementation of the MDM scheme in Tamil Nadu. Economic and Political Weekly, Vol. XLIII No.25, June 21-27, 2008.

5. Elliot, Jennifer A. 2006. An Introduction to Sustainable Development, London; 
Routledge Taylor\& Francis Group.

6. Ministry of Women and Child Development Government of India (Internet) (Available at http://www.wcd.nic.in/schemes-listing/2404) (Retrieved on July 14, 2016).

7. Ministry of Women and Child Development Government of India. Integrated Child Development Services (ICDS) Scheme. (Internet) (Available at www.anganwadi.org.in) (Retrieved on Dec.13, 2020).

8. Ministry of Women and Child Development Government of India. XII Five YearPlan Report of the Working Group, Women's Agency and Empowerment. (Internet) (Available at

http://planningcommission.nic.in/aboutus/committee/wrkgrp12/wcd/wgrep_wome n.pdf) (Retrieved on Dec. 14, 2020).

9. Singh P., Rani, S et al. 2015. International Journal of Basic and Applied Agricultural Research (Internet) (Available at https://www.cabdirect.org/cabdirect/search/?q=do\%3a\%22International+ Journal+of+Basic+and+Applied+Agricultural+Research\%22), Vol.13 No.2 pp.241244 ref.12 (Retrived on Jan.5, 2019).

10. Turnley, Jessica G. 2002. Social, Cultural and Economic Impact Assessment: A Literature Review. Albuquerque, New Mexico USA: Prepared for the Office of Emergency and Remedial Response US Environmental Protection Agency 